\title{
Characterization of 3-((carboxymethyl)thio)-
}

\author{
picolinic acid - A novel inhibitor of \\ phosphoenolpyruvate carboxykinase
}

Matthew J. Mcleodt, Anthony P. Krismanicht, Abdeljalil Assoudf, Gary I. Dmitrienkof and Todd Holyoakt*

†Departments of Biology† and †Chemistry, University of Waterloo, Waterloo, ON N2L 3G1, Canada

\section{General Synthetic Experimental}

NMR spectra were recorded on either a Bruker Avance 300 or Avance 500 spectrometer in deuterium oxide with automated calibration, in DMSO- $d_{6}$ manually calibrated to 2.49 ppm for residual DMSO- $d_{5}$, or in methanol- $d_{4}$ manually calibrated to 3.30 ppm for residual $\mathrm{CD}_{2} \mathrm{HOD}$. High resolution mass spectra were recorded on a Thermo Scientific Q-Exactive Orbitrap mass spectrometer. 


\section{Synthetic Procedures}

\section{2-((2-cyanopyridin-3-yl) thio) acetic acid}

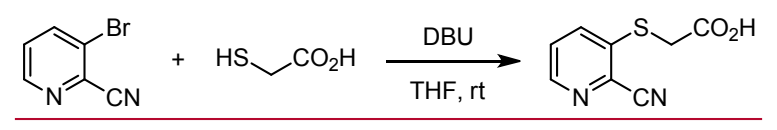

Scheme $\mathbf{s 1 . ~ I n i t i a l ~ s t e p s ~ i n ~ t h e ~ c h e m i c a l ~ w o r k u p ~ t o ~ p r o d u c e ~ t h e ~}$ desired CMP.

To a solution of 3-bromopyridine-2-carbonitrile (382.2 mg, 2.09 mmol, 1 equiv.) in THF $(10 \mathrm{~mL})$ were added mercaptoacetic acid (145.1 $\mu \mathrm{L}, 2.09 \mathrm{mmol}, 1$ equiv.) and $\mathrm{DBU}(624.6 \mu \mathrm{L}, 4.18 \mathrm{mmol}, 2$ equiv.) and the reaction was stirred at room temperature under an Ar atmosphere. The reaction was cooled, causing material to oil out and freeze. The liquid was removed. The solid was warmed and dissolved in $\mathrm{CH}_{2} \mathrm{Cl}_{2}(50 \mathrm{~mL})$ and washed with sat. aq. $\mathrm{NH}_{4} \mathrm{Cl}$. The aqueous phase was washed with $\mathrm{CH}_{2} \mathrm{Cl}_{2}$ (30 mL). To the aqueous phase was added $2 \mathrm{M} \mathrm{HCl}(40 \mathrm{~mL})$, causing it to turn yellow. The aqueous phase was washed with $\mathrm{CHCl}_{3}(60 \mathrm{~mL})$, followed by EtOAc $(3 \times 50 \mathrm{~mL})$. The combined EtOAc extracts were dried $\left(\mathrm{Na}_{2} \mathrm{SO}_{4}\right)$ and concentrated to give a pale yellow solid which did not require further purification $(246.4 \mathrm{mg}, 61 \%) .{ }^{1} \mathrm{H} \mathrm{NMR}\left(\mathrm{CD}_{3} \mathrm{OD}, 300 \mathrm{MHz}\right) \delta 8.48$ (1H, $\mathrm{dd}, J=4.7,1.4 \mathrm{~Hz}), 8.05(1 \mathrm{H}, \mathrm{dd}, J=8.3,1.4 \mathrm{~Hz}), 7.58(1 \mathrm{H}$, $\mathrm{dd}, J=8.3,4.7 \mathrm{~Hz}), 3.93(2 \mathrm{H}, \mathrm{s}) \cdot \operatorname{HRMS}-\mathrm{ESI}+(\mathrm{m} / \mathrm{z}):[\mathrm{M}+\mathrm{H}]^{+}$ calcd for $\mathrm{C}_{8} \mathrm{H}_{7} \mathrm{~N}_{2} \mathrm{O}_{2} \mathrm{~S}, 195.02227$; found, 195.02236 (Suppl. Figure 1). 


\section{3-( (carboxymethyl) thio) picolinic acid}

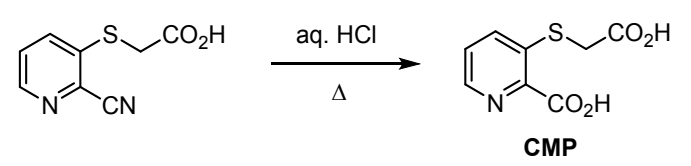

Scheme $\mathbf{s}$. Final acidification in the chemical workup to produce the desired CMP.

An aqueous $6 \mathrm{M} \mathrm{HCl}$ solution of 2-((2-cyanopyridin-3-yl)thio)acetic acid was refluxed overnight and concentrated in vacuo. The concentrate was treated with $\mathrm{TFA}_{-\mathrm{CDCl}_{3}}$ to give a suspension, and the solution was removed. The remaining solid was treated with $\mathrm{D}_{2} \mathrm{O}$ and repeatedly heated and submerged in an ultrasonic bath, resulting in near-complete dissolution. In the first attempt of the reaction, the decanted $\mathrm{D}_{2} \mathrm{O}$ NMR solution precipitated upon refrigeration. The sample was heated to restore complete dissolution. Standing at rt resulted in formation of crystals suitable for study by single-crystal x-ray diffraction, which gave an X-ray crystal structure and confirmed the intended product structure. In the second preparation attempt, the starting 
material (32.2 $\mathrm{mg}, 0.166 \mathrm{mmol})$ was refluxed in $6 \mathrm{M} \mathrm{HCl}(8 \mathrm{~mL})$ overnight. After concentration in vacuo, the same sequence of treatments brought about a lesser extent of dissolution and furnished a $\mathrm{D}_{2} \mathrm{O}$ solution whose ${ }^{1} \mathrm{H}$ NMR spectrum evidenced a mixture. A portion of the remaining solid film (2.3 $\mathrm{mg}, 6.5 \%)$ was dissolved in a weighed quantity of $\mathrm{DMSO}-d_{6}$ and its ${ }^{1} \mathrm{H}$ NMR spectrum obtained, revealing a homogeneous solution of ( (carboxymethyl)thio)picolinic acid. The DMSO-d solution of known concentration ( $w: w)$ was suitable for direct use in enzymatic studies. ${ }^{1} \mathrm{H}$ NMR $\left(\mathrm{DMSO}_{-} \mathrm{d}_{6}, 300 \mathrm{MHz}\right) \delta 8.39(1 \mathrm{H}, \mathrm{m}), 7.86(1 \mathrm{H}, \mathrm{m})$, $7.51(1 \mathrm{H}, \mathrm{m}), 3.83(2 \mathrm{H}, \mathrm{s})$ (Suppl. Figure 2); ${ }^{13} \mathrm{C} \mathrm{NMR}(125 \mathrm{MHz}$, $\left.\mathrm{DMSO}-d_{6}\right) \delta 170.3,166.8,145.9,144.8,135.6,135.2,126.1,34.1 ;$ HRMS-ESI+ (m/z) (Suppl. Figure 3): $[\mathrm{M}+\mathrm{H}]^{+}$calcd for $\mathrm{C}_{8} \mathrm{H}_{8} \mathrm{NO}_{4} \mathrm{~S}$, 214.01685; found, 214.01692. 


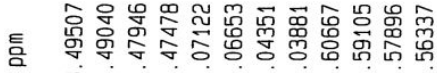

$\bigcup^{\infty}$
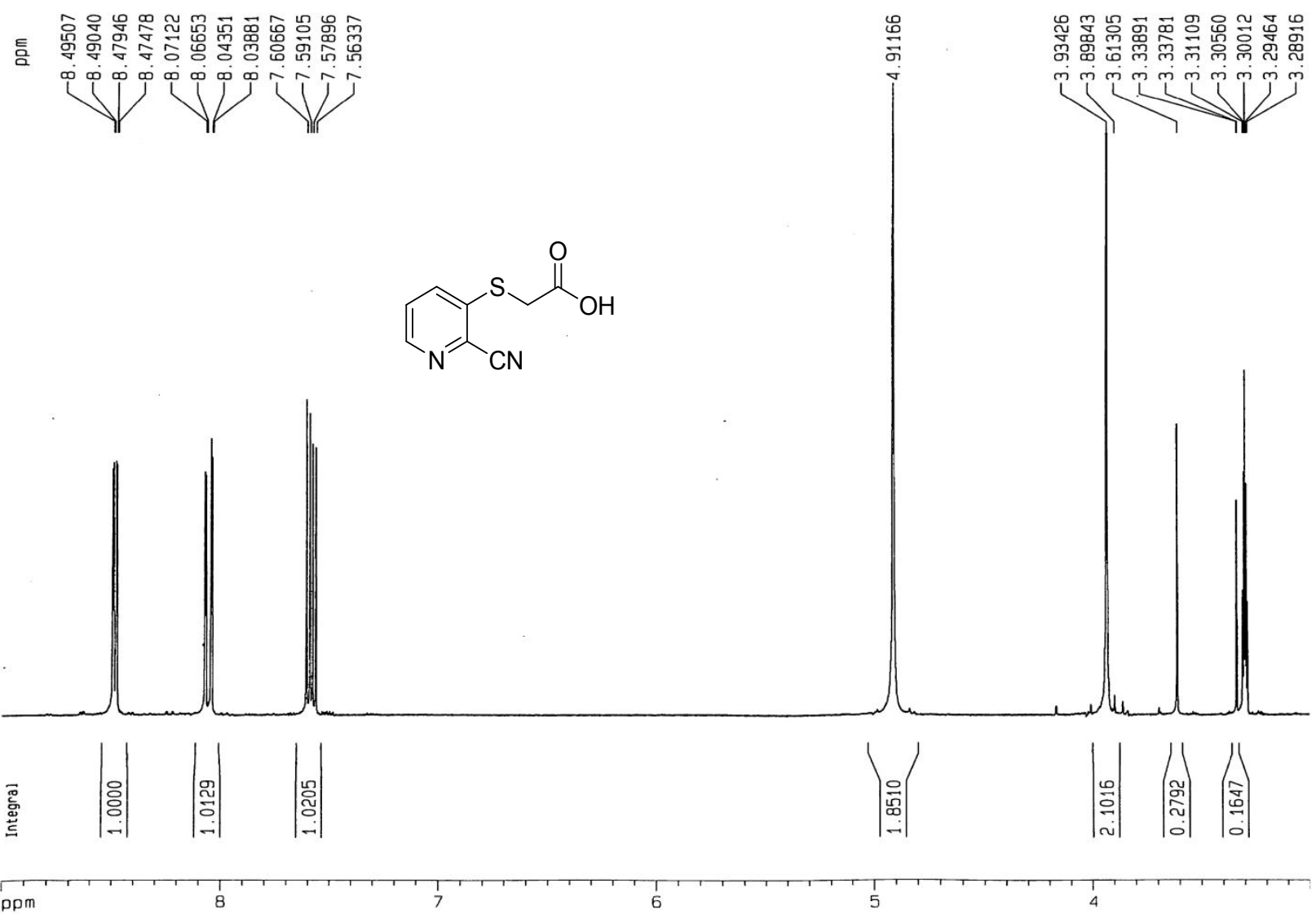

Figure s1. Proton NMR spectrum of 2-((2-cyanopyridin-3yl) thio) acetic acid (2). 


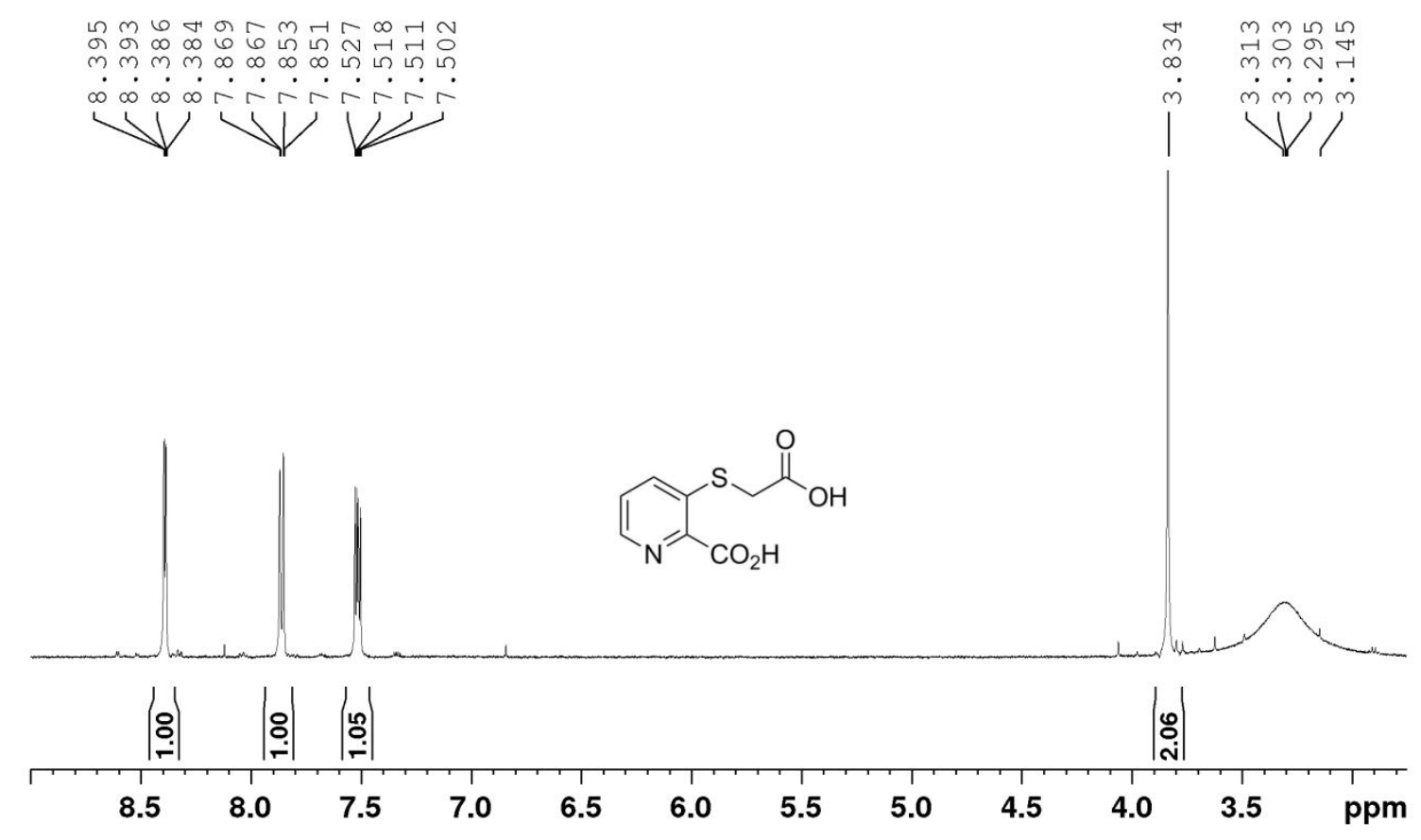

Figure S2. Proton NMR spectrum of 3-( (carboxymethyl)thio)picolinic acid (3).
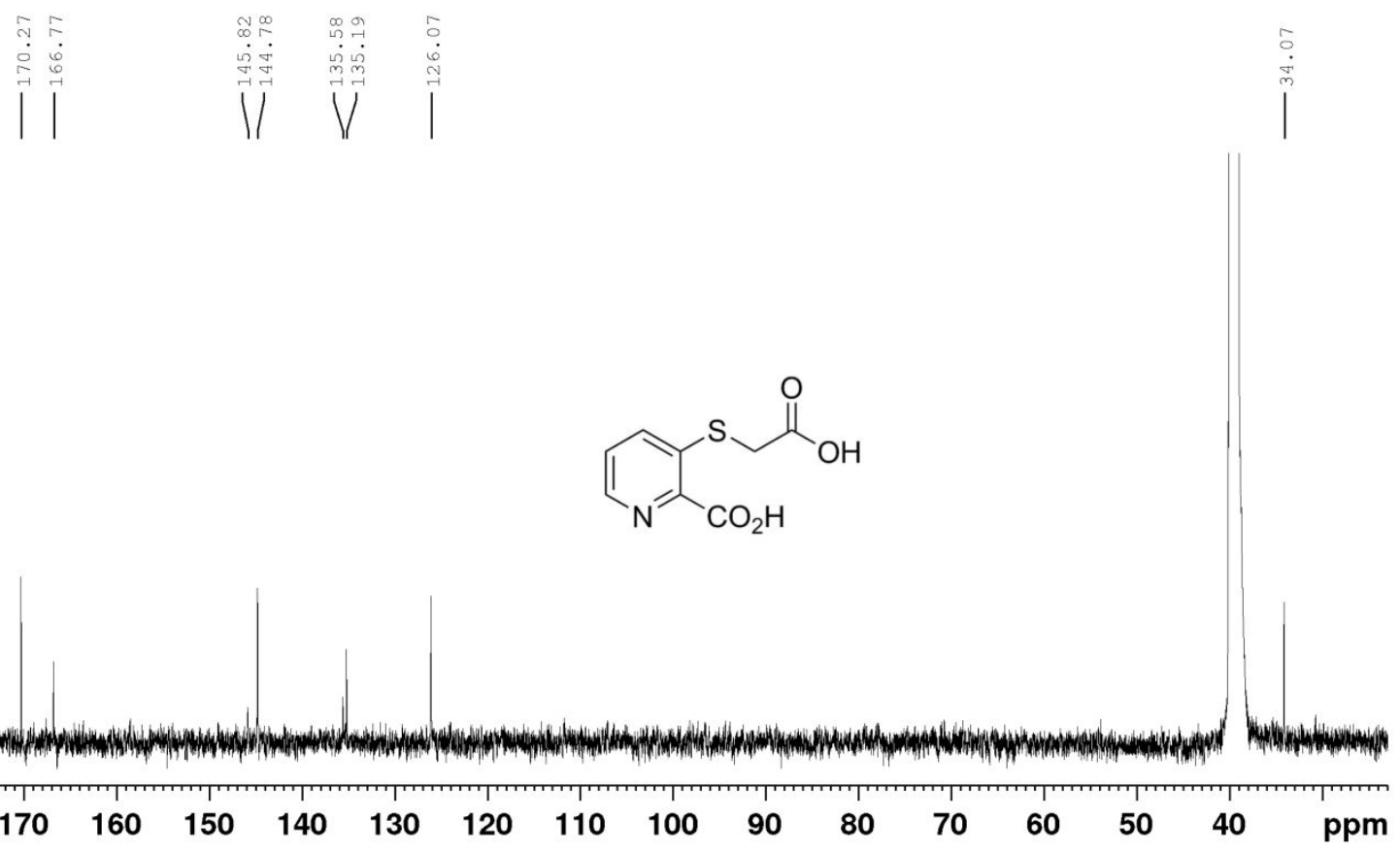

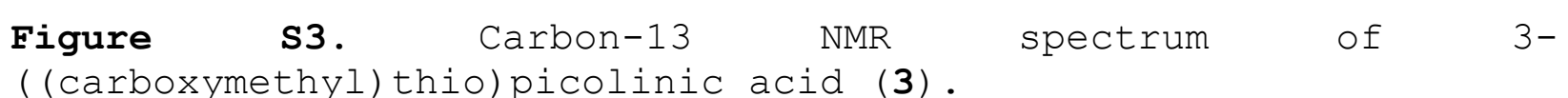




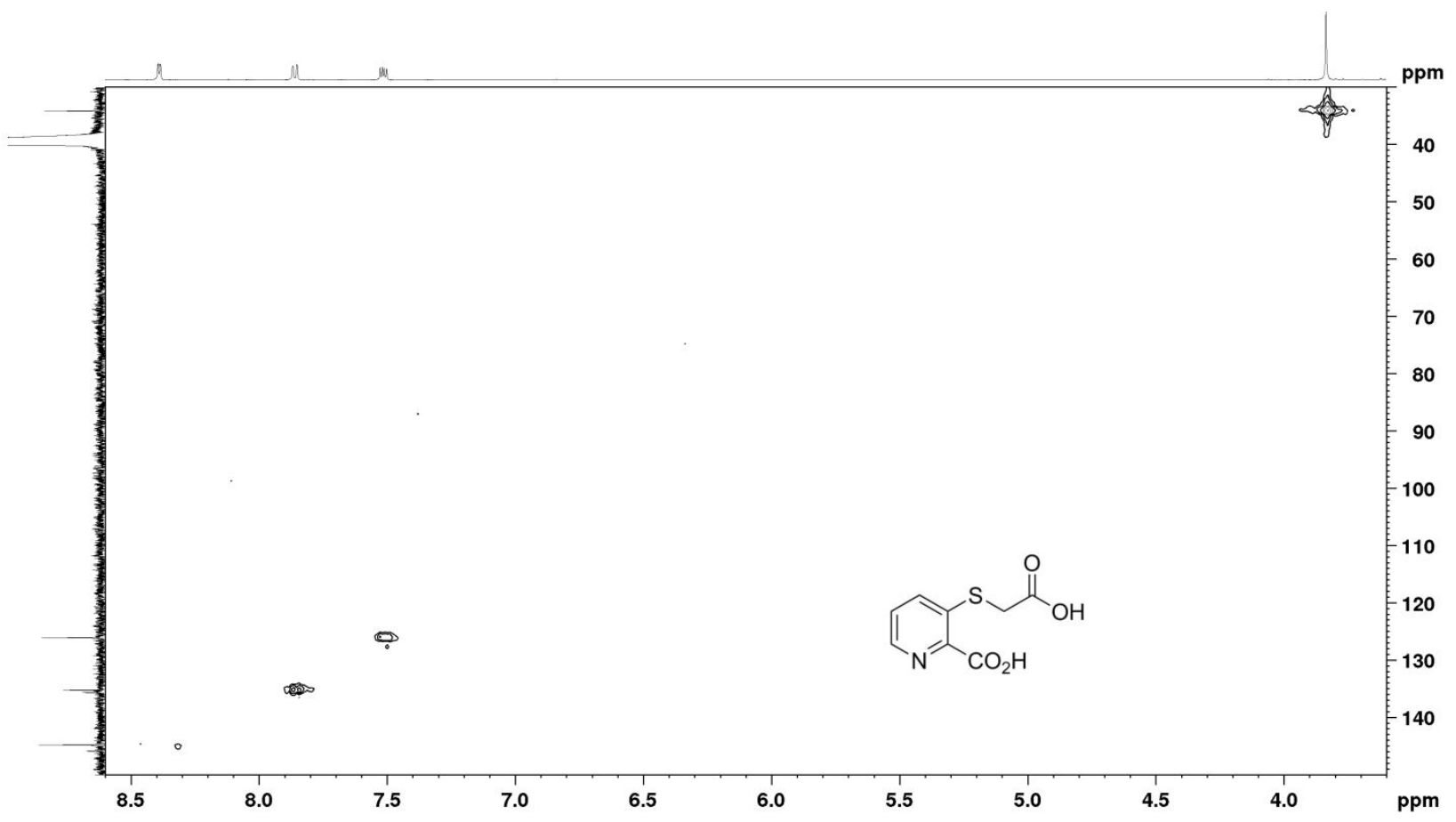

Figure s4. HMQC NMR spectrum of 3-((carboxymethyl)thio)picolinic acid (3). 


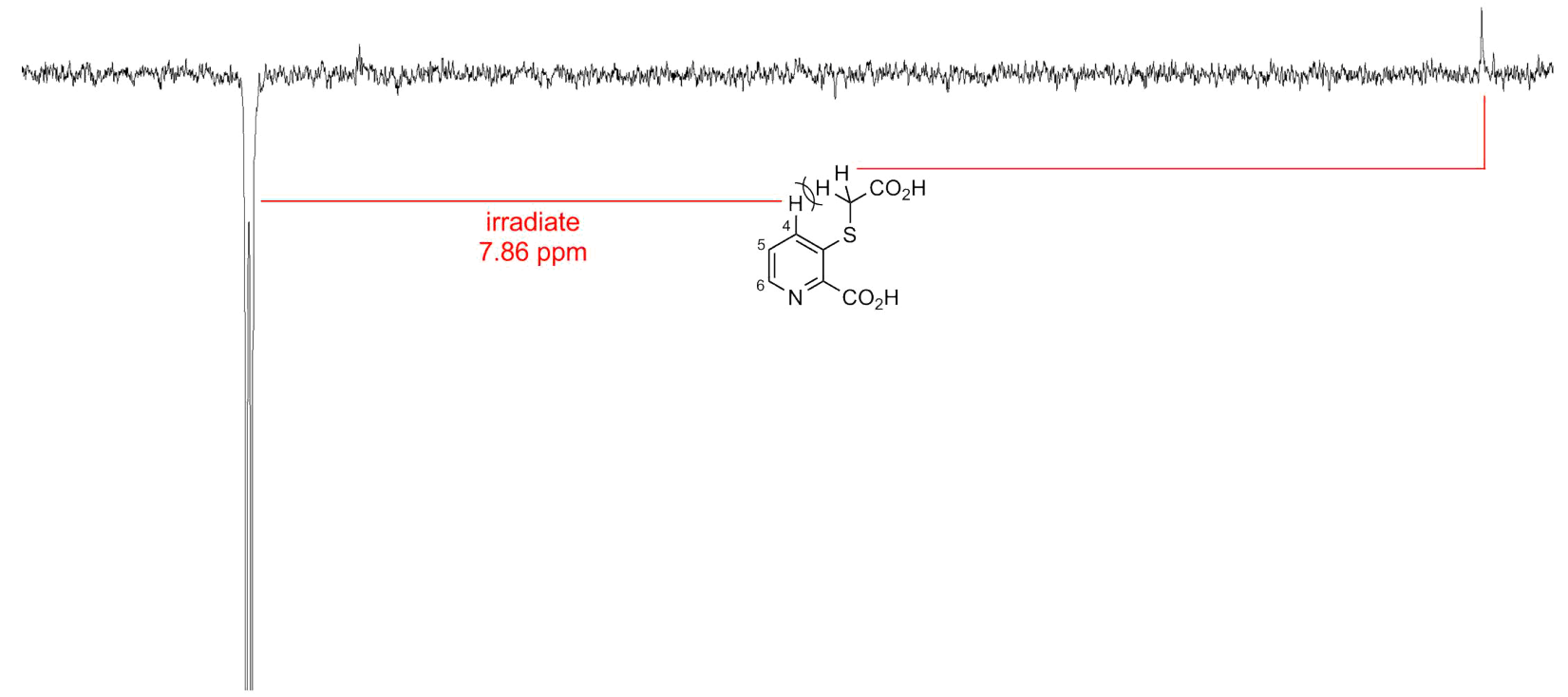

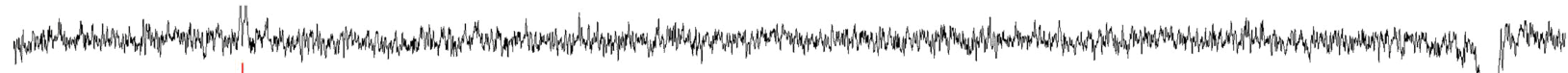
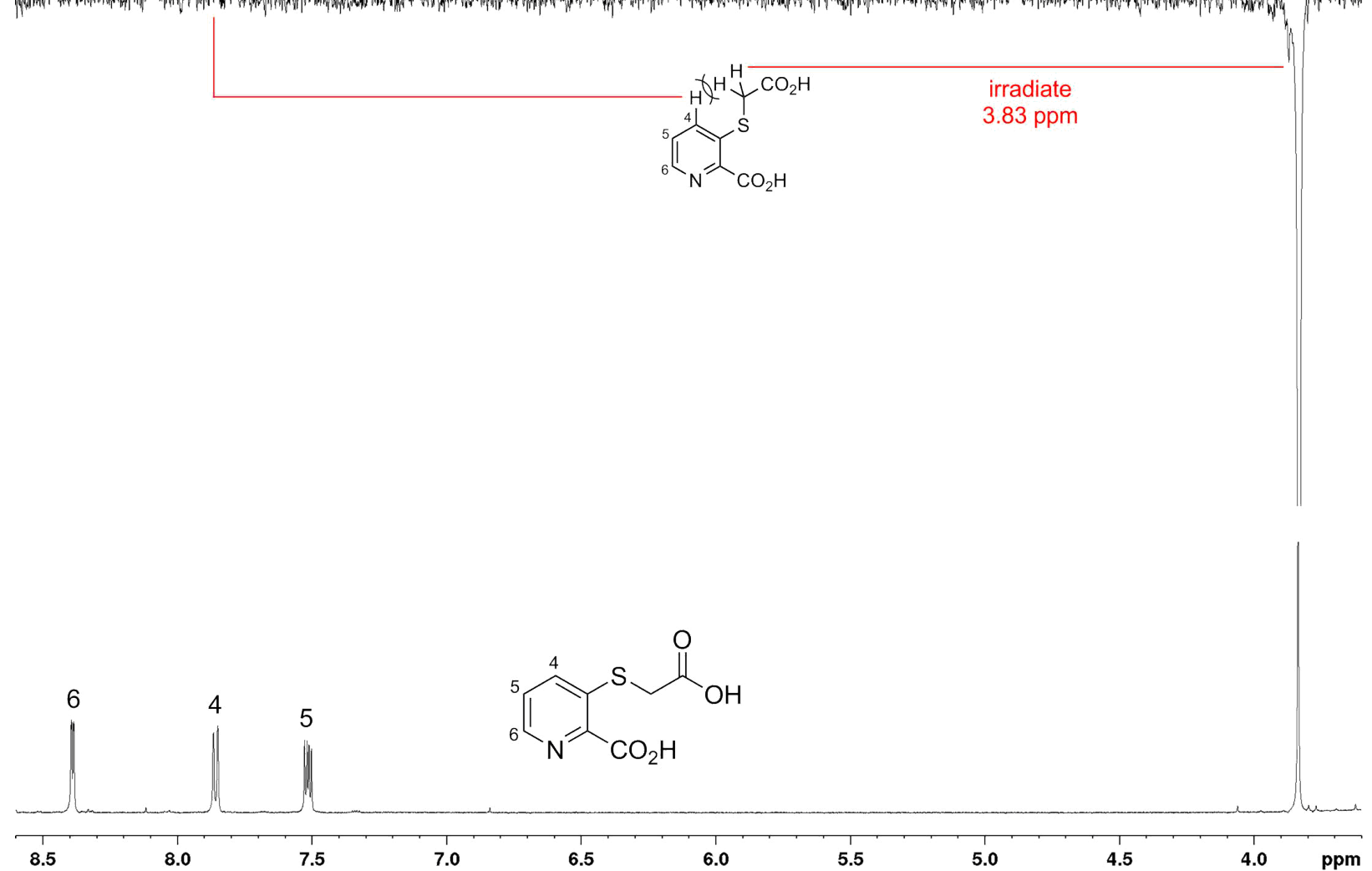

Figure S5. Difference NOE NMR spectra of 3( (carboxymethyl) thio)picolinic acid (3) 
IC $_{50}$ rCPEPCK vs
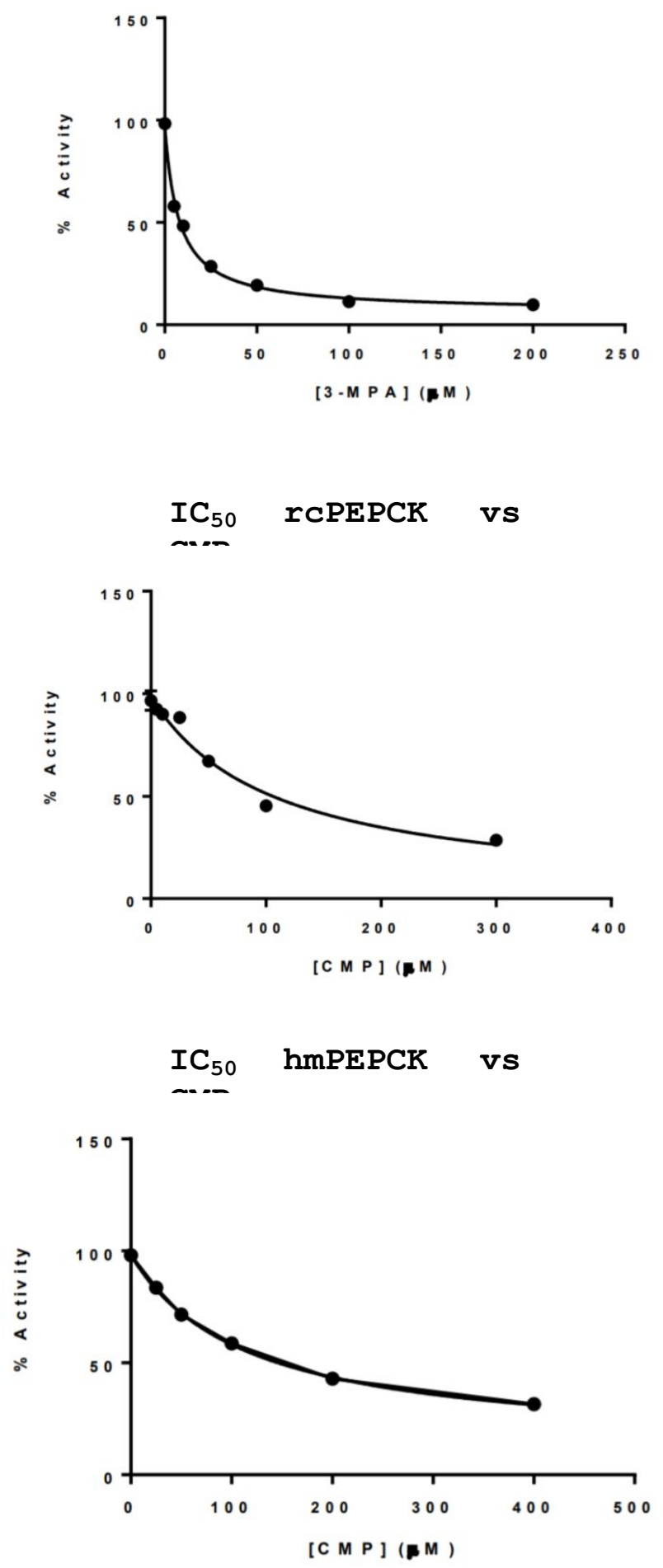
Figure $\mathbf{s 6}$ The raw IC 50 data graph of the of the various inhibitor/enzyme experiments. Error bars are contained within the points.

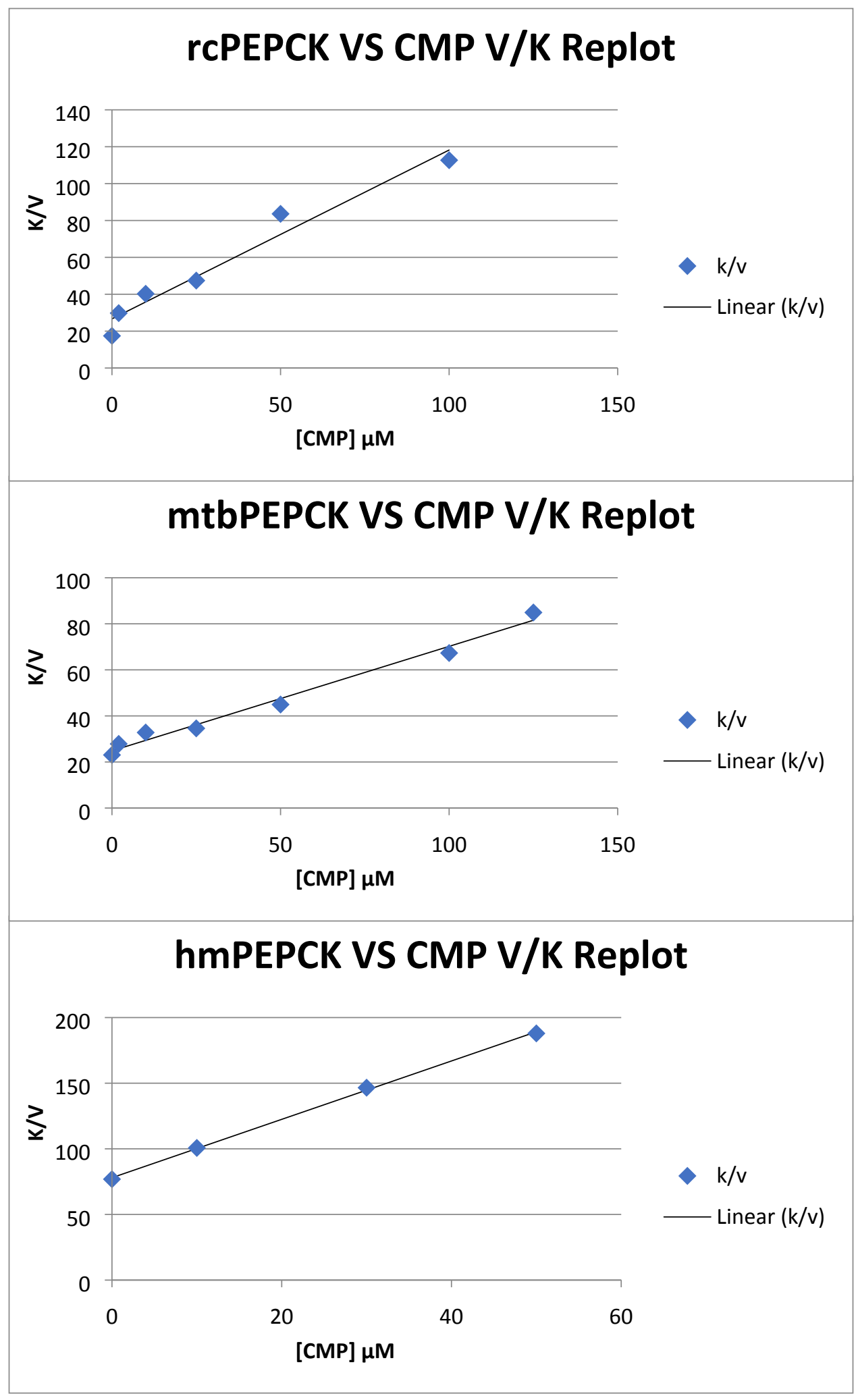


Figure s7. The raw data graphs of the $\mathrm{K} / \mathrm{V}$ effect $\mathrm{VS}$ CMP concentration for the three isozymes tested. 